\title{
Mutation Detection by Fluorescent Chemical Cleavage: Application to Hemophilia B
}

\author{
I.I. Haris, P.M. Green, D.R. Bentley, ${ }^{1}$ and F. Giannelli
}

\begin{abstract}
Division of Medical and Molecular Genetics, United Medical and Dental Schools of Guy's and St Thomas's Hospitals, London Bridge, London SE1 9RT,UK
\end{abstract}

\begin{abstract}
Chemical mismatch detection when combined with PCR or RT-PCR amplification represents one of the most efficient mutation screening methods. This procedure has been used for the analysis of both large populations of mutants and large and complex genes because it detects and locates virtually all sequence variations in segments of DNA of up to $1.7 \mathrm{~kb}$ cleaving at, and/or adjacent to, mismatches in heteroduplexes formed by target and probe DNA. By using fluorescent tags and an automatic gel scanning system, the efficiency of the method has been increased fourfold with gains also in the safety and quality control of probes and in the flexibility of the procedure. Using 12 hemophilia B patients, 8 with known mutations and 4 chosen at random, we show how the chemical mismatch cleavage of up to four DNA segments can be multiplexed and examined in a single gel lane and how the increase in efficiency thus obtained can be used either totally to maximize the DNA screened per lane or partly to locate the mutation unequivocally so that only one sequencing reaction is needed to characterize it fully.
\end{abstract}

\footnotetext{
${ }^{1}$ Present address: The Sanger Centre, Hinxton Hall, Hinxton, Cambridgeshire. CB10 1RQ, UK.
}

he need to analyze mutations rapidly in increasingly larger populations and more complex genes demands continual improvement in efficiency of the methods that are available. Chemical mismatch detection reveals any sequence change in segments of up to $1.7 \mathrm{~kb}$, and in contrast to the other two methods most used (denaturing gradient gel electrophoresis and single-strand conformational polymorphism), it locates the mutation within the segment analyzed. ${ }^{(1-6)}$ These features have made it extremely useful in the investigation of very large and complex genes, especially when used to analyze the sequence of an mRNA amplified by reverse transcriptase-PCR (RT- PCR). ${ }^{(3,4)}$

Chemical mismatch requires the hybridization of test and ${ }^{32} \mathrm{P}$-end-labeled (probe) PCR products and treatment of the resulting heteroduplexes with osmium tetroxide and hydroxylamine. These chemicals modify mismatched $\mathrm{T}$ and $\mathrm{C}$ residues, respectively, ${ }^{(1)}$ and, also sometimes matched $\mathrm{T}$ and $\mathrm{C}$ residues if they are adjacent to unpaired or mispaired bases. DNA is specifically cleaved at the modified bases by piperidine in denaturing conditions, and the products are resolved on a denaturing polyacrylamide gel. The presence of a unique band smaller than the full-length product reveals a mutation, and the size of the band indicates the distance of the mutation from one end of the molecule.

The ability to label DNA using four different fluorescent tags is a major advance that allows multiple PCR and mismatch reactions to be combined both during manipulation and gel analysis without loss of information. Thus, it al- lows a fourfold increase in throughput; it can be used to provide more precise positional information, especially in the analysis of long PCR products, and it permits long-term storage of large amounts of stable probes. This approach is applicable to the study of mutations in any gene using chemical mismatch of either amplified genomic DNA or transcripts. We describe the application of fluorescent detection techniques to the study of mutations in hemophilia B.

\section{MATERIALS AND METHODS \\ Amplification of Target and Probe DNA}

DNA was extracted from peripheral blood cells by standard procedures. ${ }^{(7)}$ Fluorescent primers for the amplification of factor IX exons were purchased from Oswel. They were first synthesized with Aminolink 2 (ABI) at the $5^{\prime}$ end and then derivatized with one of three fluorescent dyes (JOE, TAMRA, or ROX), followed by HPLC purification. ${ }^{(8)}$ The other dye-primer was synthesized directly using FLAM-phosphoramidite followed by HPLC purification. ${ }^{(9)}$ The following primers were synthesized to amplify, respectively, exons $\mathrm{a}, \mathrm{b}$ and $\mathrm{c}, \mathrm{d}, \mathrm{e}, \mathrm{f}, \mathrm{g}, \mathrm{h}$ and their flanking sequences: TAMRA-5a and TAMRA-3a; FAM-5b2 and FAM-3c; ROX-5d and ROX-3d; TAMRA-5e and TAMRA-3e; JOE-5f and JOE-3f2; FAM-5g2 and FAM-3g; JOE-5h2 and ROX-3h2. The sequence of the primers is as reported previously. ${ }^{(10)}$ Amplification of factor IX exons was performed as described previously. ${ }^{(10)}$ Probe DNA was amplified from normal genomic DNA using the fluorescently labeled primers in $100-\mu l$ reac- 
tions. Products were separated by electrophoresis, purified using GeneClean II (Bio 101), and eluted in a final volume of $20 \mu \mathrm{l}$.

\section{Fluorescent Mismatch Detection}

The chemical cleavage procedure was performed as described previously, ${ }^{(2)}$ but fluorescent detection required a $5 \times$ increase in probe and $8 \times$ increase in target DNA. Multiplexed mismatch reactions consisted of $50 \mathrm{ng}$ of each of three or four probes plus $400 \mathrm{ng}$ of each corresponding target PCR product. These were denatured in $3 \mathrm{M} \mathrm{NaCl}, 0.3 \mathrm{M}$ Tris$\mathrm{HCl}(\mathrm{pH} \mathrm{8.0)}$ ) for $5 \mathrm{~min}$, then hybridized at $65^{\circ} \mathrm{C}$ overnight. The hybrids were ethanol precipitated and resuspended in 14 $\mu l$ of $10 \mathrm{~mm}$ Tris- $\mathrm{HCl}$ ( $\mathrm{pH} 7.4$ ), $0.1 \mathrm{~mm}$ EDTA. The hybrids were then treated with hydroxylamine (final concentration, $2.3 \mathrm{~m}$ ) and osmium tetroxide (final concentration, $0.025 \%$ ) and cleaved in 1 M piperidine exactly as described. ${ }^{(2)}$ After ethanol precipitation, the pellets were resuspended in $5 \mu \mathrm{l}$ of formamide, denatured for $5 \mathrm{~min}$, electrophoresed through a standard $0.4-\mathrm{mm}$-thick, $24 \mathrm{~cm}$ $6 \%$ denaturing polyacrylamide gel run on a 373A DNA Sequencer (ABI) for $\sim 14$ $\mathrm{hr}$, and analyzed using the 672 Genescan software (ABI). Standard DNA molecular weight markers (Genescan 2500 ROX, $\mathrm{ABI}$ ) were loaded in separate lanes.

Direct sequencing of PCR products was performed as described previously. ${ }^{(10)}$

\section{RESULTS AND DISCUSSION}

The eight exons of the factor IX gene and their flanking sequences were amplified in seven sections from normal genomic DNA using fluorescently labeled primers. These PCR products (the probes) were gel purified, stored at $-20^{\circ} \mathrm{C}$, and used in place of radioactively labeled probes in the chemical mismatch procedure. $^{(2)}$ The corresponding sections from hemophilia B patients (the targets) were amplified using unlabeled primers. ${ }^{(10)}$ Multiplex 1 comprises three segments that contain exon a (labeled with TAMRA, yellow), exons $b$ and c (labeled with FAM, blue), and exon $h$ (labeled with JOE, green, at the $5^{\prime}$ end and ROX, red, at the $3^{\prime}$ end). The computer image of the gel (Fig. 1a) shows the full-size probe bands at 725 bp for exon $h$ (where the green label dominates and hides the red), $653 \mathrm{bp}$ for exon a, and 557 for exons $b$ and c. Patients UK36, UK130, UK140, and UK53 were used to test mul- tiplex 1, and mismatch bands are shown in Figure 1a. UK36 has a 10-bp deletion in exon a and so yields yellow cleavage bands with both chemicals and from both heteroduplexes at 590 nucleotides and 53 nucleotides (lanes 1,5). UK130 has a $\mathrm{C} \rightarrow \mathrm{T}$ transition at nucleotide 6364 that is 155 nucleotides from the $5^{\prime}$ end of the PCR product. A blue mismatch band of 155 nucleotides can be seen in lane 2 resulting from the hydroxylamine reaction (lane 2). Exon $\mathrm{h}$ was labeled with different dyes at the 5 ' end of its two strands; this leads to unequivocal information on the location of the mutation, and in a large segment it reduces the sequencing required to characterize fully the gene defect. To test both dyes, multiplex 1 was hybridized with two patients (UK53 and UK140) carrying mutations such that one would lead to cleavage of the sense and the other of the antisense strand of the probe. Thus, patient UK53 has a G $\rightarrow$ A transition at nucleotide 31342 resulting in a C:T mismatch that is modified by hydroxylamine and cleaved to give a red ( $\left.3^{\prime}\right)$ band of 99 nucleotides (lane 3). Because this is a red band, the mutation must lie 137 nucleotides from the red (3') end. Patient UK140 has a 1-bp deletion at nucleotide 30857 that results in a mismatch a)

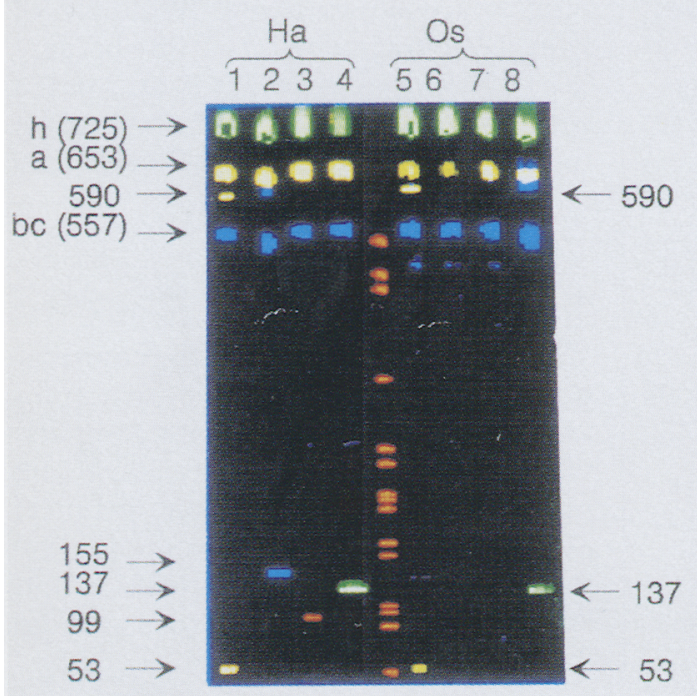

b)

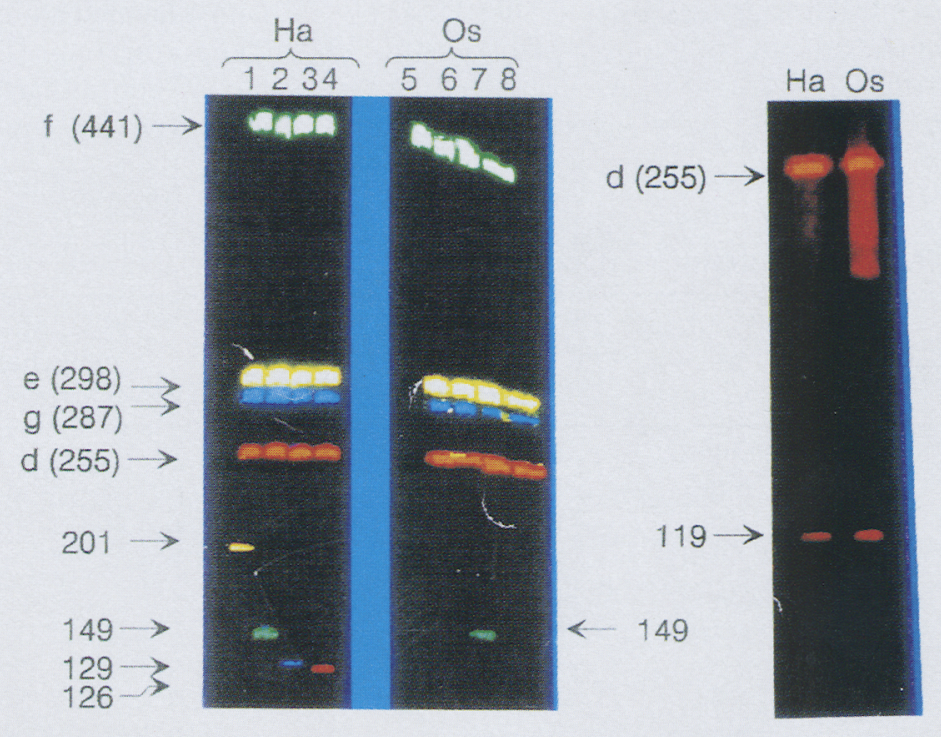

FICURE 1 Computer-generated gel display of fluorescent chemical cleavage analysis of hemophilia B genes. (a) Analysis of multiplex 1 (segment a, bc, and h) from patients UK36 (lanes 1,5), UK130 (lanes 2,6), UK53 (lanes 3,7), and UK140 (lanes 4,8). (b) Analysis of multipex 2 (segments d, e, g, f) from patients UK28 (lanes 1,5), UK179 (lanes 2,6), UK117 (lanes 3,7), and UK27 (lanes 4,8). (Ha, Os) Hydroxylamine, osmium tetroxide treated, respectively. Size of segments and cleavage bands are shown (arrows). (c) Analysis of segment $d$ of patient UK176 labeled in both probe and target strands. 
band of 137 nucleotides with both hydroxylamine and osmium tetroxide (lane 4,8).

Multiplex 2, similarly tested on four patients (UK28, UK179, UK117, UK27), shows the full-length probes at 441,298, 287 , and 255 nucleotides representing exons f (green), e (yellow), g (blue), and $\mathrm{d}$ (red), respectively, and mismatch bands (Fig. 1b). A yellow mismatch band of 201 nucleotides from the hydroxylamine reaction can be seen in lane 1 . This results from a $\mathrm{C} \rightarrow \mathrm{A}$ transversion in exon e in patient UK28 at nucleotide 17761. Patient UK179 has a $G \rightarrow T$ transversion at nucleotide 20548 (exon $\mathrm{f}$ ) that gives the expected green mismatch band with hydroxylamine at 149 nucleotides (lane 2) but also a band at the same position with osmium tetroxide (lane 6). This is presumably the result of the T:A pair at position 20547 being destabilized by the adjacent mismatched base pair and therefore modified by osmium. Patient $\mathrm{UK} 117$ has a $\mathrm{G} \rightarrow \mathrm{C}$ transversion at nucleotide 30070 (exon g), and the expected 129-nucleotides blue mismatch band resulting from this mutation can be seen in lane 3 . Finally, the test patient for exon $d$ (patient UK27) has a $\mathrm{G} \rightarrow \mathrm{A}$ transition at nucleotide 10430 that gives rise to the expected red mismatch band at 126 nucleotides (lane 4).

The fluorescent mismatch detection procedure not only has detected all known mutations tested but has also identified four new ones (Table 1). The latter are all single-base-pair substitutions $(G \rightarrow T, G \rightarrow A, A \rightarrow G, G \rightarrow C)$ affecting, respectively, exon $b$ in multi- plex 1 and exons $d, e$, and $f$ in multiplex 2 . These patients were simultaneously analyzed by the standard radioactive mismatch detection procedure, and the same results were obtained.

By combining up to four differently labeled PCR fragments in one tube and performing the mismatch reaction on this multiplex, four times the current maximum of DNA sequence can be screened in any one experiment, that is, $\sim 7 \mathrm{~kb}$ per track per chemical (assuming $4 \times 1.7-\mathrm{kb}$ segments are tested per track). This defines two alternative positions for the mutation within one amplified segment because the identity of the cleaved strand is unknown. ${ }^{2}$ Alternatively, in regions such as exon $h$ of factor IX, which are large and a frequent site of mutation, the two ends of the PCR product can be labeled with different fluorescent tags so that the gel analysis indicates which strand of the probe has been cleaved and thus defines the unique location for each mutation. This allows the use of only one sequencing reaction to complete analysis of the mutation even in long DNA segments.

The only mismatches resistant to chemical modification and cleavage are $\mathrm{G}: \mathrm{T}$ mismatches where the $\mathrm{T}$ is flanked on the $5^{\prime}$ side by a G. ${ }^{(12)}$ Such mismatches can be detected through the C:A mismatch in the alternative heteroduplex. This, however, requires labeling of the patient DNA so that the mismatched $\mathrm{C}$ is in a labeled strand. By labeling both target and normal DNA and hybridizing them in equimolar amounts (100 ng), one can ensure the detection of these

TABLE 1 Mutations Characterized

\begin{tabular}{|c|c|c|c|c|c|c|}
\hline $\begin{array}{l}\text { Patient } \\
\text { no. }\end{array}$ & Color & Chemical & $\begin{array}{l}\text { Band } \\
\text { size }\end{array}$ & Exon & $\begin{array}{l}\text { Nucleotide } \\
\text { change } \\
\text { type }\end{array}$ & Position \\
\hline *UK36 & yellow & $\mathrm{Ha}, \mathrm{Os}$ & 590,53 & & $\Delta 10$ & $111-120$ \\
\hline *UK130 & blue & $\mathrm{Ha}$ & 155 & bc & $\mathrm{C} \rightarrow \mathrm{T}$ & 6364 \\
\hline *UK53 & red & $\mathrm{Ha}$ & 99 & $\mathrm{~h}$ & $\mathrm{G} \rightarrow \mathrm{A}$ & 31342 \\
\hline${ }^{\star} \mathrm{UK} 140$ & green & $\mathrm{Ha}, \mathrm{Os}$ & 137 & h & $\Delta 1$ & 30857 \\
\hline${ }^{\star} \mathrm{UK28}$ & yellow & $\mathrm{Ha}$ & 201 & e & $C \rightarrow A$ & 17761 \\
\hline${ }^{*}$ UK179 & green & $\mathrm{Ha}, \mathrm{Os}$ & 149 & $\mathrm{f}$ & $\mathrm{G} \rightarrow \mathrm{T}$ & 20548 \\
\hline${ }^{*} \mathrm{UK} 117$ & blue & $\mathrm{Ha}$ & 129 & $\mathrm{~g}$ & $\mathrm{G} \rightarrow \mathrm{C}$ & 30070 \\
\hline ^UK27 & red & $\mathrm{Ha}$ & 126 & $\mathrm{~d}$ & $\mathrm{G} \rightarrow \mathrm{A}$ & 10430 \\
\hline + UK111 & blue & $\mathrm{Ha}$ & 293 & bc & 1bplns & 6471 \\
\hline UK176 & red & $\mathrm{Ha}$ & 119 & d & $\mathrm{G} \rightarrow \mathrm{A}$ & 10437 \\
\hline + UK57 & yellow & Os & 260 & $\mathrm{e}$ & $A \rightarrow G$ & 17810 \\
\hline + UK131 & green & $\mathrm{Ha}, \mathrm{Os}$ & 175 & f & $\mathrm{G} \rightarrow \mathrm{C}$ & 20524 \\
\hline
\end{tabular}

(*) Mutations previously characterized; ${ }^{(11)}(+)$ gel not shown.

(Ha) Hydroxylamine; (Os) osmium tetroxide. $(\Delta)$ Deletion.

\section{ACKNOWLEDGMENTS}

We gratefully acknowledge the contribution of S. Saad and G. Rowley, who provided samples and carried out comparative radioactive experiments. We thank Applied Biosystems for their technical assistance. This work was supported by the Medical Research Council, Action Research, the Generation Trust, and the Spastics Society.

\section{REFERENCES}

1. Cotton, R.G.H., N.R. Rodrigues, and R.D. Campbell. 1988. Reactivity of cytosine and thymine in single-base-pair mis- 
matches with hydroxylamine and osmium tetroxide and its application to the study of mutations. Proc. Natl. Acad. Sci. 85: 4397-4401.

2. Montandon, A.J., P.M. Green, F. Giannelli, and D.R. Bentley. 1989. Direct detection of point mutations by mismatch analysis: Application to hemophilia B. Nucleic Acids Res. 17: 3347-3358.

3. Naylor, J.A., P.M. Green, A.J. Montandon, C.R. Rizza, and F. Giannelli. 1991. Detection of three novel mutations in two hemophilia A patients by rapid screening of the whole essential region of factor VIII gene. Lancet 337: 635-639.

4. Roberts, R.G., M. Bobrow, and D.R. Bentley. 1992. Point mutations in the dystrophin gene. Proc. Natl. Acad. Sci. 89: 23312335.

5. Sheffield, V.C., D.R. Cox, L.S. Lerman, and R.M. Myers. 1989. Attachment of a 40-base-pair G + C-rich sequence (GCclamp) to genomic DNA fragments by the polymerase chain reaction results in improved detection of single-base changes. Proc. Natl. Acad. Sci. 86: 232-236.

6. Hayashi, K. 1991. PCR-SSCP: A simple and sensitive method for detection of mutations in the genomic DNA. PCR Methods Applic. 1: 34-38.

7. Miller, S.A., D.D. Dykes, H.F. Polesky. 1988. A simple salting out procedure for extracting DNA from human nucleated cells. Nucleic Acids Res. 16: 1215.

8. Giusti, W.G. and T. Adriano. 1993. Synthesis and characterization of 5 '-fluorescent dye labeled oligonucleotides. $P C R$ Methods Applic. 2: 223-227.

9. Theisen, P., C. McCollum, K. Upadhya, K. Jacobsen, H.N. Vu, and A. Andrus. 1992. Fluorescent dye phosphoramidite labelling of oligonucleotides. Tetrahedron Lett. 33: 5033-5036.

10. Green, P.M., D.R. Bentley, R.S. Mibashan, I.M. Nilsson, and F. Giannelli. 1989. Molecular pathology of hemophilia B. EMBO J. 8: 1067-1072.

11.Giannelli, F, P.M. Green, K.A. High, S. Sommer, M.-C. Poon, M. Ludwig, R. Schwaab, P.H. Reitsma, A. Yoshioka, and G.G. Brownlee. 1993. Hemophilia B: Database of point mutations and short additions and deletions, 4th ed., 1993. Nucleic Acids Res. 21: 3075-3087.

12. Forrest, S.M., H.-H.M. Dahl, D.W. Howells, I. Dianzani, and R.G.H. Cotton. 1991. Mutation detection in phenylketonuria by using chemical cleavage of mismatch: Importance of using probes from both normal and patient samples. Am. J. Hum. Genet. 49: 175-183.

Received November 16, 1993; accepted in revised form February 10, 1994. 




\section{Mutation detection by fluorescent chemical cleavage: application to hemophilia B.}

I I Haris, P M Green, D R Bentley, et al.

Genome Res. 1994 3: 268-271

References This article cites 12 articles, 3 of which can be accessed free at: http://genome.cshlp.org/content/3/5/268.full.html\#ref-list-1

\section{License}

Email Alerting

Receive free email alerts when new articles cite this article - sign up in the box at the Service top right corner of the article or click here.

\section{Affordable, Accurate Sequencing.}

To subscribe to Genome Research go to: https://genome.cshlp.org/subscriptions 